\title{
A lei de cotas para pessoas portadoras de deficiência nas empresas brasileiras: impacto e possíveis alternativas
}

\author{
The law of quotas for people with disabilities \\ in Brazilian companies: the impact and possible alternatives
}

Abstract Thispaper consists of a theoretical analysis of the impact of the Brazilian law establishing quotas for people with disabilities in companies with one hundred or more employees, as well as the possible impact of some alternative legal measures: incentives (fiscal incentives and tradable rights) and information disclosure policies. The analysis is based on work regarding the efficacy of legal normsin general, and particularly the literature concerning the cost and cognitive effects of thosenorms. Given its exclusively theoretical character, the paper does not affirm the superiority of any regulatory strategy over the current law, but draws attention to the likely reasons for the failure of the quota system and for the potential and inconveniences of its proposed alternatives. Key words People with disabilities, Law of quotas, Impact, Incentives, Information disclosure policies
Resumo 0 trabalho consisteem uma análiseteórica acerca do impacto da legislação que impõe cotas para pessoas portadoras de deficiência em empresas com cem ou mais empregados no Brasil, bem como de al gumas solu ções legais al ternativas: incenti vos (incentivos fiscais e comercialização do direito a não contratar) e medidas de regulação pela informação. As referências teóricas do artigo compõem-se de trabalhos sobre a eficácia das normas jurídicas em geral e, em particular, de trabaIhos atinentes aos efeitos de custo e cognitivos dessas normas. Considerando-se tratar-se de análise exclusivamente teórica, o trabalho não chega a concluir pela superioridade das demais estratégias de regulação examinadas frente à lei de cotas, limitando-se a chamar a atenção para as possíveis cau sas do fracasso desta última epara o potencial e os inconvenientes das alternativas aventadas. Palavras-chave Pessoas portadoras de deficiência, Lei de cotas, Impacto, Incentivos, Regulação pela I nformação 
Introdução

A legislação brasileira combate a discriminação contra pessoas portadoras de deficiência (PPD) mediante a imposição de cotas em empresas com mais de cem empregados. Essas cotas são de 2\% para empresas com até duzentos empregados, $3 \%$ para empresas com 201 até quinhentos empregados, 4\% para empresas com 501 até mil empregados e 5\% para empresas com mais de mil empregados ${ }^{1}$.

Dados empíricos sugerem, porém, que as vagas legalmente reservadas às PPD estão longe de ser totalmente preenchidas ${ }^{2,3}$. A fim de levantar hipóteses sobre por que isso acontece, o pre sente trabalho faz uma análise teórica acerca do impacto da lei de cotas no combate a diferentes espécies de discriminação a que estão sujeitos os trabalhadores com deficiência. Depois, esta análise é estendida para al gumas soluções legais alternativas às cotas, como incentivos (incentivos fiscais e a comercialização do direito a não contratar) e medidas de regulação pela informação ou information disclosure.

0 trabalho é organizado como segue. A próxima seção é dedicada a possíveis causas da discriminação contra PPD na decisão de contratar. A seção subsequente trata do impacto da lei de cotas, consideradas todas as possíveis causas de discriminação antes descritas. Seguem-se duas seções estimando os efeitos de soluções legais alternativas, a primeira delas sobre medidas de incentivo (incentivo fiscal e comercialização do direito a não contratar) ea segunda sobre políticas de informação baseadas exclusivamente na divulgação da informação.

Empresas, decisão de contratar e discriminação contra a PPD

Considere se, para começar, a hipótese de que a decisão de contratar seja "racional" (no sentido de maximizadora dos ganhos da empresa) e perfeitamente informada. Trata-se, é claro, de uma hipótese heroica, mas que, não obstante, mostrase útil para a análise feita a seguir. Admitindo-se que, por uma exigência legal, o empregador não esteja livre para diferenciar salários, a decisão de contratar, no caso de empregadores racionais e perfeitamente informados, éuma função exclusiva da produtividade do trabalhador, já que, com salários fixos, os resultados da empresa variarão de acordo com a produtividade dos empregados. Sob essas condições, PPD serão admitidas à me dida da sua produtividade, de modo que, entre uma PPD e outro candidato não portador de de ficiência, a primeira será preterida se, e somente se, estiver em desvantagem em relação ao segundo quanto à capacidade para produzir.

Como segunda hipótese, considere-se agora que a decisão de contratar seja uma decisão racional, mas que, diferentemente do postulado acima (e de modo mais plausível), ocorra sob circunstâncias deinformação imperfeita. Assim sendo, a decisão de contratar segue como função da produtividade do trabalhador, mas esta não é conhecida de antemão pelo empregador, de maneira que a decisão racional passa a ser também uma função dos custos a incorrer para obter informações sobre a produtividade dos vários candidatos a uma vaga. 0 corolário disso é que a decisão de contratar não será necessariamente postergada até que o empregador reúna todas as informações relevantes, já que o custo para conseguir essas informações pode, em al gum ponto, superar o benefício que a empresa auferirá com a contratação do trabalhador mais produtivo.

Pode-se, então, aventar que PPD acabem racionalmente preteridas na decisão de contratar ainda que não sejam, de fato, menos produtivas do que o concorrente escolhido (discriminação por produtividade média). Para entender 0 porquê, suponha-se que deficiência e produtividade estejam em alguma medida correlacionadas ou, ao menos, pareçam estar. Ainda que a deficiência seja um indicador imperfeito da produtividade, a correspondência entre as duas variáveis podeser (ou parecer) robusta o suficiente para que, considerando-se os custos que o empregador teria de suportar para se informar sobre a produtividade dos candidatos a uma vaga, a solução ótima, do ponto de vista da maximização dos resultados da empresa, seja discriminar com base na deficiência.

Uma terceira hipótese é a que se afasta da suposição de racionalidade. De acordo com ela, a decisão de não contratar PPD é, ao menos em alguns casos, uma decisão irracional, no sentido de não se dever nem à baixa produtividade do candidato portador de deficiência, nem à baixa produtividade média do grupo de PPD ao qual elepertence. Na hipótese sob exame, a decisão de recusar o trabalhador com deficiência é, portanto, caracterizada pelo preconceito ou "viés" (discriminação por viés), que tanto pode ser consciente (caso no qual se poderia falar de uma "preferência pela discriminação") como inconsciente ou "implícita"

Um conjunto final de hipóteses a considerar diz respeito particularmenteàs empresas às quais 
se aplica a lei de cotas, isto é, empresas com cem ou mais empregados. N estas, é muito comum que a decisão de contratar fique a cargo de alguém cuja relação com os diretores da companhia ou seus acionistas caracterize-se como uma relação de agência ${ }^{5}$, isto é, uma relação na qual uma das partes (o agente) exerce atividade do interesse de outra (o principal). No caso, agente é o diretor de recursos humanos ou qualquer outro empregado a quem fique atribuída a decisão de contratar, sendo principais os seus superiores hierárquicos e, mediatamente, os acionistas. A exemplo de outras relações de agência, a relação em questão é marcada pela potencial divergência entre os interesses do agentee do principal, e pelo risco, daí decorrente, de o primeiro se conduzir de maneira contrária aos interesses desteúltimo.

A relação de agência subjacente à decisão de contratar em organizações complica a análise da discriminação das PPD. Em circunstâncias deinformação imperfeita, o principal tem de se basear em sinais para avaliar se a conduta do agente éfiel aos seus (do principal) interesses. Assim, se a contratação de uma PPD for um sinal de infidelidade, 0 agente (diretor de recursos humanos ou outro), por saber disso, pode preterir o candidato com deficiência mesmo informado de que esse é o candidato mais apto. Em outras palavras, as informações do agente sobre a superioridade do candidato com deficiência não bastam se não são também conhecidas pelo principal (CEO ou outro) e se, à falta de tais informações, o principal valer-se da baixa produtividade mé dia das PPD para avaliar se a escolha feita pelo agente atende aos seus interesses. Algo similar vale para o caso em que haja um viés do principal contra a admissão de PPD, isto é, em que a suspeita contra a decisão do agente de contratar um trabalhador com deficiência não seja mera decorrência da desinformação do principal sobre as aptidões dos candidatos e da menor produti vidade média das PPD. Se o agente está a par desse viés, pode recusar o candidato com deficiência mesmo sabendo ser essa uma decisão irracional à vista não só das informações que ele, agente, possui acerca dos candidatos à vaga, mas também das informações gerais sobre a produtividademédia de PPD à disposição do principal. Por fim, igual resultado se verifica ainda nos casos em que, erroneamente, 0 agentereputea contratação deuma PPD como sinal de contrariedade aos interesses do principal. Assim, mesmo quando não constitua, para o principal, um sinal de violação dos seusinteresses pelo agente(já que, por hipótese, o principal não acredita em uma menor produtividade média das PPD, nem tem viés contrário à contratação dessas pessoas), a decisão de admitir o trabalhador com deficiência pode ser dificultada por uma avaliação equivocada do agente acerca do modo como essa decisão é encarada pelo principal.

\section{Impacto da Lei de cotas}

Qual o impacto da lei de cotas sobre a discriminação das PPD? Considere-se, para começar, a hipótese da discriminação por produtividade individual, na qual, como observado acima, trata-se a decisão de contratar como decisão racional e perfeitamente informada. 0 impacto da lei de cotas, em tal hipótese, é o de criar um custo adicional à contratação de trabalhadores sem deficiência sempre que essa contratação ocorrer em detrimento da cota destinada às PPD. Devido a esse custo, a decisão de contratar um trabal hador com deficiência podetornar-sea decisão ótima (isto é, maximizadora dos ganhos da empresa), ainda quando a produtividade desse trabaIhador esteja aquém da decandidatos rivais, tudo a depender da relação entre o custo correspondente à perda de produtividade (isto é, da diferença entre a produtividade do trabalhador admitido e a do candidato mais apto entre os preteridos) eo custo decorrente do não cumprimento da lei. Sobre esseúltimo ponto, contudo, notese que o custo suportado pela empresa que não preenche a cota é uma função da sanção cominada e da probabilidade de essa sanção ser, de fato, aplicada ${ }^{6}$.

A hipótese da discriminação por produtividade individual tem, ainda, as seguintes implicações no que se refere à eficácia da lei de cotas. Primeiro, à medida que essa lei dê lugar, de fato, à contratação de PPD, esta ocorrerá para os cargos em relação aos quais a diferença de produtividade entre o candidato portador de deficiência e o candidato preterido por força da lei seja menor. Admitindo-seque esses cargos sejam os mais mal remunerados, tem-se uma explicação para evidências sobre a baixa média salarial das PPD ocupantes das vagas reservadas nas empresas brasileiras². Segundo, considerando-se que a diferença entre a produtividade das PPD e dos demais trabal hadores seja uma função da gravidade da deficiência, a lei também induz as empresas a preencher as cotas com portadores de deficiências menos graves ${ }^{2}$.

Por fim, não é de descartar que uma medida como a lei de cotas tenha o condão de reduzir a 
discriminação baseada na produtividade individual devido ao seu impacto "moralizante", graças ao qual a contratação de PPD passe a se verificar também em detrimento do objetivo de maximizar lucros, isto é, mesmo em casos nos quais o custo a arcar com a infringência à norma legal seja inferior ao da perda de produtividade que a decisão de contratar trabalhador deficiente acarreta. Esse possível efeito persuasivo da lei será examinado adiante, quando se voltar a tratar da hipótese em que 0 aumento do custo atrelado à discriminação não seja, por si só, o bastante para que a causa dessa discriminação desapareça (hipótese da discriminação por viés).

A análise do impacto da lei de cotas a partir da hipótese da discriminação por produtividade média é bastante similar à anterior, e isso ao menos no caso em que haja, de fato, uma corre lação entre deficiência e produtividade. Uma vez que tal correlação se verifique, ainda que ignore quais das PPD candidatas a emprego são menos aptas por causa da deficiência, o empresário sabe que, em média, a produtividade dessas pessoas é inferior à dos trabal hadores comuns eque, portanto, suportará uma perda ao contratar um número significativo das primeiras. Supondo-se que as decisões do empresário procurem maximizar os resultados da empresa, a contratação dePPD dependerá então da relação entre o custo advindo da perda de produtividade e aquele a arcar com o descumprimento da lei, o qual, como visto acima, é uma função da sanção cominada e da probabilidade da sua aplicação. Além disso, nos casos em que o custo da violação legal seja robusto o suficiente para induzir à contratação de PPD, espera-se que isso ocorra com as pessoas e para os cargos em relação aos quais a diferença de produtividade média entre PPD e trabal hadores não deficientes seja menor, com uma tendência, pois, à seleção para cargos com mais baixa remuneração e de portadores de deficiência menos grave.

Uma implicação diferenteseverifica nos casos em quea correlação entre deficiência eprodutividade seja meramente aparente, isto é, em que as empresas estejam equivocadas ao atribuir a certo grupo de PPD uma produtividade média inferior à de trabal hadores sem deficiência. Em tais casos, a lei de cotas pode ter 0 efeito de corrigir a informação dos empregadores sobre trabalhadores portadores de deficiência, eliminando a discriminação por produtividade média. Esse efeito é limitado, entretanto, aos cargos para os quais a deficiência não seja, de fato, um fator deprodutividade, o que pode, mais uma vez, favorecer 0 aproveitamento de trabalhadores com deficiência leveepara cargos debaixa remuneração. Além disso, a discriminação por produtividade média somente pode ser erradicada à medida que as empresas cumpram a lei e corrijam, à base do desempenho das PPD contratadas, a informação acerca da produtividade média dessas pessoas.

Há, contudo, também um efeito reverso a considerar para as circunstâncias de informação imperfeita às quais a hipótese da discriminação por produtividade média se refere. Quando a relação entre deficiênciae produtividademédia é mal conhecida, toda contratação de PPD que tenha lugar sem exigência legal constitui um indicador positivo acerca da produtividade média do grupo ao qual esse trabalhador pertence. Com a criação das cotas, todavia, a mensagem acaba truncada, já que a contratação de uma PPD arrisca-se então a ser entendida não mais como indicador da capacidade para produzir do trabalhador admitido (e, por consequência, da capacidade média do grupo ao qual ele pertence), mas como mero resultado da exigência legal. I sso pode contribuir para disseminar a falsa ideia de uma correlação entre deficiência e produtividade média e, à medida que falteà lei poder dissuasório, ser um empecilho ao fim da discriminação baseada em tal produtividade.

Outro eventual efeito benéfico da lei de cotas éo de aumentar a produtividade média das PPD, contribuindo, assim, para o fim da discriminação baseada nessa produtividade. Para entender como isso pode ocorrer, é preciso ter em vista que a baixa produtividade média das PPD é às vezes uma consequência não da deficiência mesma, mas de características do local de trabalho ou da falta de preparo ou disposição dos demais empregados para trabalhar com colegas portadores de deficiência. Assim, à medida que a lei seja cumprida, o aumento das contratações pode atenuar ou até fazer desaparecer a redução de produtividade média das PPD causada por fatores outros que não a deficiência mesma, preve nindo, em consequência, a discriminação devida à produtividade média.

A análise do impacto da lei de cotas torna-se mais espinhosa quando se tem em vista a hipótese da discriminação por viés. Diferentemente das duas anteriores, essa é uma discriminação que não se relaciona ao custo da contratação de PPD, e que, portanto, não se elimina mediante a imposição às empresas de um custo igual ou maior decorrente da inobservância à legislação. Isso não significa que esse custo (uma função, como visto, da sanção instituída em lei e da pro- 
babilidade de sua aplicação em caso de violação) seja incapaz de arrefecer o viés contrário à sele ção de trabalhadores com deficiência ou, pelo menos, às suas consequências, mas o modo como isso ocorre é mais difícil de prever do que nas vezes em que a recusa a contratar PPD tenha lugar unicamente em razão do custo.

Quando a discriminação é baseada em uma preferência pela não contratação de PPD (e não em um cálculo de custo-e-benefício), e o que se pretende da lei é que combata essa preferência mesma ao invés de apenas a decisão que dela resulta, a questão da capacidade da lei para se opor ao viés decisório do empregador se traduz como questão da capacidade para alterar as preferências dos atores submetidos às normas legais. Infelizmente, é pouco o que se sabe acerca das condições sob as quais a legislação logra alterar as preferências dos atores mediante a internalização das suas normas. Cogita-se que essa internalização (ou impacto "moralizante") do sistema jurídico seja uma função do prestígio da autoridade que dita as normas ou das pessoas que se comunicam ao público para endossá-las?. Além disso, sugere-se que a internalização pode ser auxiliada pelo temor de perda da reputação ${ }^{8}$, de modo que, para alguns atores, o abandono da preferência pela discriminação seria mediado pelo referido temor. 0 papel de uma norma legal antidiscriminatória seria, em tal caso, o de comunicar aos atores que a discriminação é socialmente reprovada, fazendo-os antecipar o referido prejuízo à reputação acarretado pela discriminação. Com a sua realização dificultada, a tendência, em tais circunstâncias, seria a preferência pela discriminação desaparecer ${ }^{8}$.

A análise do combate à discriminação mediantea internalização denormas se complica quando se considera o risco de, ao invés de auxiliar, a lei servir de empecilho a essa internalização. A hipótese aqui é que uma medida como a lei de cotas pode não apenas fal har na tentativa de eliminar a preferência pela discriminação mediante a internalização de uma norma antidiscriminatória, como ainda dificultar que essa internalização ocorra por outros meios. Esse efeito indesejável, que em Psicologia se conhece como efeito de superjustificação $0^{9,10}$, é atribuído a medidas que, ao tornarem saliente o castigo ou a recompensa advindos de um certo comportamento, reduzam o sentido de autonomia dos atores ou desviem a sua atenção de outros motivos, "intrínsecos" (isto é, não atrelados a consequências) pelos quais o mesmo comportamento poderia se verificar. Aplicada ao caso em questão, a ideia é quea lei de cotas poderia ter o efeito cognitivo de atrelar a contratação de PPD à ameaça da sanção legal e, ao fazê-lo, deixar à sombra outras razões, sobretudo morais, favoráveis a essa contratação.

Por fim, pode-se ainda cogitar que a lei reduza a discriminação não porque logre eliminar a preferência de alguns empregadores pela discriminação dePPD, mas devido a outra preferência capaz, ocasionalmente, de se contrapôr à primeira. Um exemplo de preferência assim é aquela pelo cumprimento da lei, a qual, caso presente, levaria a decisão do empresário com consciente viés discriminatório a ser descrita como uma função da relação entre duas preferências antagônicas, uma pela contratação de trabalhadores sem deficiência eoutra pelo respeito à lei. A ideia desta última é encontrada em estudos que mostram ser a obediência à legislação devida menos ao poder dissuasório da sanção do que à legitimidade das normas legais, a qual varia, no entanto, de acordo com fatores como o procedimento por meio do qual as normas são estabelecidas e 0 modo como os atores a elas submetidos são tratados pelas autoridades ${ }^{11,12}$.

Duas previsões contraditórias são feitas ainda acerca do impacto de medidas de ação afirmativa como a lei de quotas. Alega-se, de um lado, que essas medidas se mostram um remé dio eficaz contra o viés discriminatório ao provocar um aumento da diversidade no local de trabalho ${ }^{13}$. A ideia é que o viés implícito contra pessoas pertencentes a determinados grupos é em parte causado pela infrequência com que essas pessoas são vistas em alguns locais de trabaIho, de modo que, ao forçar a sua admissão a esses locais, a reserva de vagas teria um efeito redutor da discriminação. Por outro lado, há o receio de que as cotas deem força a clivagens e ao estigma de que são vítimas as pessoas a quem beneficiam eacabem por se mostrar, assi m, mais um fator de discriminação ${ }^{14}$.

\section{Incentivos}

Em sentido amplo, "incentivo" é toda consequência, positiva ou negativa, atrelada à ação de outrem e capaz de induzir al guém a realizar uma conduta. A lei de cotas não deixa de ser, em tal sentido, um incentivo à contratação de PPD, já que comina uma sanção (multa) para as empresas que não contratarem PPD na quantidade legalmente estipulada. Muitas vezes, no entanto, a palavra "incentivo" é usada em sentido mais restrito, para referir medidas legais que, ao invés de 
prescrever certo comportamento, limitam-se a atrelá-lo a determinada consequência, estimulando, assim, a sua ocorrência ${ }^{15}$.

Tratar-se-á nesta seção de duas medidas de incentivo alternativas à lei de cotas. A primeira é a de conceder vantagens fiscais para empresas que contratem PPD (incentivo fiscal). A ideia, já cogitada no Brasil ${ }^{16}$, seria eximir as empresas da obrigação de contratar trabalhadores com deficiência e, ao mesmo tempo, remunerar, por meio de benefícios fiscais, aquelas que o fizerem. Uma segunda medida de incentivo consisteem permitir que o direito a não contratar trabalhadores seja comercializado (comercialização do direito a não contratar).

Para empresas nas quais a seleção de trabaIhadores se dê demaneira a maximizar o lucro, 0 incentivo fiscal somente levará à contratação de PPD se a sua vantagem superar o custo com a perda de produtividade ocasionada por essa contratação, calculada esta última pela diferença de produtividade entreo trabalhador com deficiência admitido e o melhor candidato preterido (quando a informação é perfeita) ou pela diferença de produtividade média entre trabal hadores com e sem deficiência (sob informação imperfeita). Além disso, um empregador racional tratará de contratar PPD cuja diferença de produtividade (individual ou estimada pela média) em relação a outros trabalhadores seja menor, decorrendo daí uma tendência à sel eção de pessoas com deficiência branda e para cargos de baixa remuneração.

Uma hipótese a considerar é a de que, ao não impor um dever aos empregadores, uma medida de incentivo fiscal seja, em comparação com a lei de cotas, uma expressão de reprovação menos viva à discriminação de que são vítimas as PPD e, portanto, menos apta a fazer com que os atores internalizem uma norma contrária a essa discriminação. Além disso, tanto quanto a lei de cotas, o incentivo fiscal se sujeita a produzir um efeito psicológico de superjustificação $0^{9,10}$, reduzindo a importância de qualquer motivação para a contratação de trabalhador com deficiência que não a obtenção da vantagem legalmente prevista.

Em linhas gerais, a ideia da comercialização do direito a não contratar PPD consiste em permitir que, ao invés de preencher uma cota de vagas para trabalhadores com deficiência, uma empresa contribua para um fundo público ${ }^{17}$ ou, alternativamente, remunere outras empresas que mantenham um contingente dePPD superior ao da cota legalmente fixada. Trata-se aí de uma estratégia regulatória comumente defendida para o controle da poluição ${ }^{18}$, mas que é também cogitada para outros fins, entre eles o combate à discriminação ${ }^{19}$.

Admitindo-se, uma vez mais, que a decisão sobre contratar ou não uma PPD se baseie em um cálculo de custo-e-benefício, uma diferença entre uma "solução de mercado" como a da comercialização do direito a contratar eas estratégias de regulação anteriormente examinadas consiste em quea primeira faz concentrar a contratação de trabalhadores com deficiência em empresas nas quais a diferença de produtividade (individual ou média) entre uma PPD e um trabalhador sem deficiência seja menor, quando não nula (hipótese na qual a medida legal seria inócua, já que a contratação do trabalhador com deficiência ocorreria de qualquer maneira). Ao concentrar a contratação de PPD em certas empresas, a comercialização do direito a contratar acirraria a tendência, já verificada nos casos anteriores, à seleção detrabal hadores com deficiência maislevee para cargos menos bem remunerados.

Uma crítica comum a programas de comercialização na área da preservação ambiental é a que se refere a o conteúdo expressivo e corresponde efeito cognitivo de uma medida legal que confere o direito a exercer uma atividade socialmente danosa ou moralmente condenável (tal como o direito a poluir ou, no caso em exame, 0 direito a não contratar PPD) ou que trata o bem em jogo (o meio ambiente, a inclusão do trabaIhador com deficiência, etc.) como comercializável. 0 receio équea mensagem latente da medida legal torne a conduta acerca da qual o direito é concedido mais palatável ${ }^{20,21}$, bem como que a permissão à comercialização degrade o bem ao qual alude, fazendo-o parecer menos merecedor de respeito ${ }^{20}$. Sobre isso, contudo, é oportuno notar o fato de que a reação dos atores a duas políticas públicas materialmente equivalentes pode variar de acordo com o modo como cada uma destas é descrita (o que em Psicologia se designa como "efeito de configuração", o framing effect ${ }^{22}$ ). Assim, mesmo quequal quer medida pela qual sepermita a uma empresa pagar (seja a uma outra empresa, seja a um fundo público) para não ter de contratar PPD seja, no sentido legal da palavra, uma medida que confere o direito a não contratar essas pessoas (e, nesse sentido, o direito a discriminar), o modo como essa medida é designada publicamente (por exemplo, evitando-se o uso de palavras como "direito" e "venda") podeminimizar o risco dequese verifiquem os efeitos deletérios temidos pelos críticos da comercialização ${ }^{23}$. 


\section{Regulação pela informação}

Designam-se como estratégias de regulação pela informação ou information disclosureas que exigem dos regulados que prestem informações acerca da sua atividade, sem impor, entretanto, qualquer limite a essa atividade ${ }^{15}$. Para o tema aqui examinado, o uso dessa estratégia corresponderia a determinar que as empresas divulguem o número ou o percentual de PPD que empregam, bem como, eventualmente, informações sobre as espécies de deficiência dos trabaIhadores empregados, cargos, salário médio e tempo médio de permanência na organização. Em contrapartida, uma medida de regulação pela informação não proibiria a discriminação contra PPD, nem, tampouco, estabeleceria uma cota de vagas a ser preenchida com essas pessoas.

Em relação à lei de cotas e ao que acima se designou como medidas de incentivo, o que a re gulação baseada na informação faz é, em primeiro lugar, substituir o incentivo legal ou formal correspondente à consequência legalmente prevista por um incentivo informal, dado pela reação de certos atores às informações, positivas ou negativas, acerca do tratamento dispensado pela empresa a trabalhadores com deficiência24. Estes atores são: consumidores, que podem ter preferência pelos produtos de empresas socialmente responsáveis e, em particular, de empresas que favoreçam a inclusão de PPD; investidores, que também podem preferir empresas socialmente responsáveis ou tratar a responsabilidade social como sinal do valor do investimento; trabalhadores, que podem preferir (ou não) trabalhar para organizações contratantes de PPD; autoridades, que podem reagir à divulgação de informações negativas sobre o desempenho social das empresas com medidas mais duras do que a mera exigência da informação; outros empresários, que podem ter preferência por empresas socialmente responsáveis ou temer a reação do público e das autoridades a informações negativas sobre o de sempenho social de outras empresas, sobretudo quando do mesmo setor de atividade.

Tratando-se do impacto da informação como meio de induzir à contratação de PPD, é importante notar como a eficácia de uma medida de regulação pela informação é função das expectativas dos atores acima elencados, da influência dessas expectativas sobre o comportamento dos mencionados atores e da influência, por sua vez, destes últimos sobre o comportamento empre sarial. No que se refere às expectativas sobre 0 comportamento empresarial em relação às PPD, é de se considerar que elas tanto podem estar aquém como além do desejável, isto é, tanto pode ocorrer deo público considerar aceitável queuma empresa mantenha um percentual de trabalhadorescom deficiência inferior ao ideal (eaténulo) como demandar o preenchimento de uma cota superior à que seria razoável exigir.

À medida, porém, que a decisão sobre contratar ou não uma PPD esteja a serviço da maximização do lucro, não basta que atores como os anteriormenteelencados possuam alguma expectativa acerca do comportamento empresarial sobre a inclusão de PPD, isto é, que não sejam indiferentes ao percentual de trabalhadores com deficiência empregados em uma determinada empresa. M esmo que o público seja sensível ao fato de trabal hadores com deficiência serem preteridos por algumas empresas, uma condição para que a informação tenha impacto é que essa sensibilidade dê lugar a decisões relevantes para as empresas em questão. É sabido, por exemplo, que, embora uma quantidade considerável de consumidores se manifeste disposta a comprar, ainda que a um maior preço, produtos "verdes" ou "éticos", é muito menor o número dos que de fato o fazem ${ }^{24}$. Entre os motivos para que a informação sobre o desempenho social de uma empresa não provoque a reação esperada estão a desconfiança sobre a veracidade dos dados divulgados e a incapacidade dos atores para lidar com informações em número e grau de dificuldade muito elevados ${ }^{25}$.

O sucesso de uma política de informação de pende, ainda, da suscetibilidade das empresas à influência de outros atores. Essa suscetibilidade varia de acordo com as características do meio (ou "ambiente institucional") em que as empresas atuam, o que justifica avaliar o potencial das políticas de informação tendo em vista as particularidades do capitalismo de cada país $5^{26,27}$. Assim, em países nos quais seja menor a dependência do investimento via mercado de ações ou bancário, haja menos concorrência, grande oferta de mão-de-obra, baixa capacidade estatal regulatória e associações empresariais pouco significativas, menor será, respectivamente, a suscetibilidade das empresas à influência de investidores, consumidores, trabalhadores, governo e outras empresas.

Deve-se atentar, porém, para o risco de exagerar a importância defatores estratégicos quando se trata da resposta de uma organização empresarial às expectativas quea cercam. A literatura neoinstitucionalista alerta para a possibilidade de que, em al guma medida, a conduta organi- 
zacional trate de atender a essas expectativas por si mesmas, isto é, independentemente do benefício que a legitimação da organização aos olhos de certos atores venha a proporcionar ${ }^{28}$. Ainda, portanto, que a difusão da informação sobre a recusa a contratar PPD se mostre incapaz de influenciar as decisões de atores relevantes para a empresa, é possível que uma mudança de comportamento se verifique caso a informação divulgada sirva para alimentar certa "pressão difusa" para que a organização se legitime.

Por último, aventa-se também que, independentemente de pressões externas, uma legislação que obrigue empresas a prestar certas informações pode surtir algum efeito ao tornar essas informações conhecidas pel os dirigentes da empresa mesma, ou, ao menos, ao salientá-las. Uma razão para isso é que a informação pode chamar a atenção para a ineficiência dos processos de produção. Por exemplo, ao exigir de uma empresa que informe sobre o impacto ambiental da sua atividade, a lei pode tornar perceptível aos dirigentes o mau uso de certos recursos e dar lugar, assim, a providências capazes de reduzir a poluição e, ao mesmo tempo, aumentar os lu$\operatorname{cros}^{29}$. Algo análogo vale para a informação sobre a contratação de trabalhadores com deficiência, que pode revelar uma baixa frequência de admissão de PPD contrária ao objetivo de maximização do lucro (admitindo-se, aí, que a produtividade do trabalhador com deficiência não seja inferior à dos demais), seja por um viés dos empregados encarregados da seleção, seja pelo temor infundado desses últimosquanto ao modo como a contratação de uma PPD seria encarada pelos seus superiores.

Por fim, admite-se que a obtenção da informação contribua para o "desenvolvimento moral" da companhia ${ }^{30}$, fazendo internalizar em seus gestores e nos demais empregados uma norma em favor do comportamento desejado (no caso, a inclusão de PPD). Uma estratégia de regulação pela informação não é substancialmente distinta, a esse respeito, de medidas que, como a lei de cotas, prescrevam certo comportamento, uma vez que o impacto moralizante dessas últimas não é assegurado pela aplicação da sanção que geralmente as acompanha. Tal como a lei de cotas, no entanto, a eficácia persuasiva de uma lei queselimitea exigir das empresas que informem sobre a contratação de PPD depende do sentido com que a disposição legal e suas consequências ( no caso de uma lei de informação, a informação divulgada) são recebidas, podendo variar, por exemplo, de acordo com uma predisposição dos atores envolvidos a considerar reprovável a conduta acerca da qual a informação se refere. Isso significa que, em comunidades nas quaisuma ideia geral de responsabilidade social empresarial esteja menos difundida, é também menor a chance de uma medida legal alusiva à discriminação no local de trabalho produzir algum re sultado que não o conseguido à custa da ameaça de sanção ou da pressão externa exercida sobre a empresa.

\section{Consideraçõesfinais}

O presente trabalho realizou uma análise teórica do impacto da lei de cotas para a contratação de PPD em empresas brasileiras e de estratégias de regulação al ternativas, como incentivos (incentivosfiscais e comercial ização do direito a não contratar) e medidas de regulação pela informação. Embora insuficiente, por si só, para aconselhar (ou desaconselhar) o uso de qualquer dos meios de regulação cogitados, tal análise é importante por proporcionar hipóteses a serem testadas empiricamente, bem como por chamar a atenção dos encarregados da elaboração de políticas públicas para as razões do eventual fracasso de medidas tradicionais de comando-e-controle (das quais a atual lei de cotas é exemplo) e para soluções alternativas a essas medidas.

Por certo, o rol de medidas para a garantia do direito ao trabalho de PPD não se limita às que foram acima examinadas. Entre as soluções deixadas de fora da análise encontram-se algumas destinadas ao aperfeiçoamento (ao invés da substituição) dalei decotas, tal como, por exemplo, uma que fizesse frente à tendência a contratar trabalhadores com deficiência mais branda mediante a estipulação de subcotas em favor de trabalhadores cuja deficiência, devido à gravidade, constitua, nas circunstâncias atuais, um empecilho à contratação. N ão custa ainda mencionar que, para o combate à discriminação resultante de decisões empresariais maximizadoras do lucro, uma estratégia capaz de levar ao cumprimento da atual de lei de cotas consiste em ofere cer treinamento aos trabalhadores com deficiência e reduzir, assim, a diferença de produtividade entre esses e outros trabalhadores.

A respeito das estratégias de regulação alternativas, outra omissão da análise feita aqui consiste em não ter cogitado sobre o emprego dessas estratégias concomitantemente à lei de cotas. As políticas de regulação baseadas na informação estão, em especial, entre as que podem ser 
aplicadas simultaneamente a normas tradicionais de comando-e-controle, e não apenas em substituição a estas últimas ${ }^{31}$, o que leva a pensar nas medidas de difusão da informação como medidas destinadas não ao aumento "espontâneo" (isto é, não legalmente coagido) do contingente de trabalhadores com deficiência empregados, mas ao preenchimento das cotas estabelecidas em lei. Infelizmente, dado o limite de espaço, 0 exame detalhado dessa alternativa teve que ser deixado para outra ocasião.

\section{Agradecimentos}

0 autor agradece à Fundação de Amparo à Pesquisa do Estado do Rio Grande do Sul (FAPERGS) pelo apoio financeiro. 


\section{Referências}

1. Brasil. Decreto 3.298 de 20 de dezembro de 1999 Dispõe sobre a Política Nacional para a Integração da Pessoa Portadora de Deficiência, consolida as normas de proteção, e dá outras providências. Diário Oficial da União 1999; 21 dez.

2. Ribeiro MA, Carneiro R. A inclusão indesejada: as empresas brasileiras face à lei de cotas para pessoas com deficiência no mercado de trabalho. Organizações \& Sociedade 2009; 16(50):545-564.

3. Araujo JP, Schmidt A. A inclusão de pessoas com necessidades especiais no trabalho: a visão de empresas e instituições educacionais especiais na cidade de Curitiba. Rev Brasileira de Educação Espe cial 2006; 12(2):241-254.

4. Greenwald AG, Krieger LH. Implicit bias: scientific foundations. California Law Review 2006; 94(4):945968.

5. Jensen MC, Meckling WH. Theory of the firm: managerial behavior, agency costs and ownership structure. Journal of Financial Economics 1976; 3:305360.

6. Becker GS. Crime and punishment: an economic approach. Journal of Political Economy 1968; 76(2): 169-217.

7. Sunstein CR. On the expressive function of law. University of Pennsylvania Law Review 1996; 144(5):2021-2054.

8. M cAdams RH. The origin, development, and regulation of norms. Michigan Law Review 1997; 96(2): 338-433.

9. Deci EL. Effects of externally mediated rewards on intrinsic motivation. Journal of Personality and Social Psychology 1971; 18(1):105-115.

10. Lepper MR, Greene D, Nisbett RE. Undermining children's intrinsic interest with extrinsic reward: $A$ test of the "overjustification hypothesis". Journal of Personality and Social Psychology 1973; 28(1):129137.

11. Tyler TR. Procedural fairness and compliance with the law. Swiss Journal of Economics and Statistics 1997; 133(2/2):219-240.

12. Paternoster R, Bachman R, Brame R, Sherman LW Do fair procedures matter? The effect of procedural justice on spouse assault. Law and Society Review 1997; 31(1):163-204.

13. Jolls $C$, Sunstein $C R$. The law of implicit bias. California Law Review 2006; 94(4):969-996.

14. Krieger LH. Civil rights perestroika: intergroup re lations after affirmative action. California Law Review 1998; 86(6):1.251-1.338.

15. Pildes $R H$, Sunstein $C R$. Reinventing the regulatory state. University of Chicago Law Review 1995; 62(1):1 130

16. Câmara rejeita incentivo fiscal para empresa que contratar idoso e deficiente. Agência Câmara de Notícias 2011; Nov 11. [acessado 2012 set 4]. Disponível em: http://www2.camara.gov.br/agencia/ noticias/TRABALH O-E-PREVIDENCIA/205356CAM ARA-REJEITA-INCENTIVO-FISCAL-PARAEM PRESA - Q UE - CONTRATAR - I D OSO - E DEFICIENTE.html.
17. Neri M. As empresas e as cotas para pessoas com deficiência. Conjuntura Econômica 2003; 57:58-60.

18. Ackerman BA, Stewart RB. Comment: reforming environmental law. Stanford Law Review 1985; 37(5):1333-1365.

19. M ashaw JL. Implementing quotas. Georgetown Law Journal1991; 79(6):1769-1765

20. Kelman S. What price incentives? Economists and the environment. Boston: Auburn House;1981.

21. Frey BS. Motivation as a limit to pricing. Journal of Economic Psychology 1993; 14:635-664.

22. Tverski A, Kahneman D. The framing of decisions and the psychology of choice. Science 1981; 211(4481):453-458.

23. Nash JR. Framing effects and regulatory choice. N otre Dame Law Review 2006; 82(1):313-372.

24. Auger $P$, Devinney TM. Do what consumers say matter? The misalignment of preferences with unconstrained ethical intentions. Journal of Business Ethics 2007; 76:361-383.

25. Weil D, Fung A, Graham M, Fagotto E. The effectiveness of regulatory disclosure policies. Journal of Policy Analysis and M anagement 2006; 25(1):155181

26. Zanitelli LM. Empresas, responsabilidade social e políticas de informação obrigatória: aplicação ao caso brasileiro. No prelo 2012.

27. Blackman A. Alternative pollution control policies in developing countries. Review of Environmental Economics and Policy 2010; 4(2):234-253.

28. DiMaggio PJ, Powell WW. The iron cage revisited: institutional isomorphism and collective rationality in organizational fields. American Sociological Review 1983; 48(2):147-160.

29. Karkkainen BC. Information as environmental regulation: TRI and performance benchmarking, precursor to a new paradigm? Georgetown Law Journal 2001; 89(2):257-370.

30. Hess D. The three pillars of corporate social reporting as new governance regulation: disclosure, dialogue and development [working paper, Michigan Ross School] [Documento da Interenet]. [acessado 2012 ago 10]. Disponível em: http://deepblue.lib. umich.edu/bitstream/2027.42/60425/1/1112-DH ess. pdf.

31. Afsah S,Vincent JR. Putting pressure on polluters: Indonesia's PROPER programme. A case study for the $\mathrm{H}$ arvard Institute for International Development 1997 Asia Environmental Economics Policy Seminar. USA: International Resources Group, USA $H$ arvard Institute for International Development; 2000.[acessado 2012 ago 16]. Disponível em: http:/ /web.worldbank.org/archive/website01004/WEB/ IMAGES/PUTTINGP.PDF

Artigo apresentado em 10/10/2012

Aprovado em 11/11/2012

Versão final apresentada em 19/11/2012 